\title{
RANCANG BANGUN KENDALI LAMPU MENGGUNAKAN WEMOS D1 MINI DENGAN PUSAT KENDALI MEDIA SOSIAL TELEGRAM
}

\author{
${ }^{1}$ Ihsan Kamil Teja Sumarna, ${ }^{2}$ Satrio Nugroho, ${ }^{3}$ Aldi Suryanto, ${ }^{4}$ Dolly Virgian Shaka Yudha Sakti ${ }^{*}$ \\ ${ }^{1}$ Jurusan Teknik Informatika, Fakultas Teknologi Informasi, \\ Universitas Budi Luhur, Jakarta Selatan, 12260 \\ ${ }^{1}$ satrionugroho091@gmail.com, ${ }^{2}$ aldysuryanto009@gmail.com, ${ }^{3}$ dolly.virgianshaka@budiluhur.ac.id
}

\begin{abstract}
.
Basic electricity tariffs are increasing and the number of uses of electrical equipment is one reason for every people to saving. One of the biggest contributors of electricity is lighting. Effective and efficient tools are needed to control the lights so that they can quickly and precisely turn on and off the lights. Light control using a microcontroller connected to the internet become solution in this study. Microcontroller on Wemos D1 Mini is used for the central system, while the social media telegram is the control application. Wemos D1 Mini is connected to the relay module to turn lights on and off. Wemos D1 Mini is connected to the internet via wifi so telegrams can communicate with it. A telegram account is made specifically as a bot to take orders from users who control electricity. The bot account is implanted on Wemos D1 Mini. The user's private telegram account is used to communicate with bot accounts. Users can turn on, turn off and view the lights conditions by giving commands to the bot account. The tools was testing to internet connection, in seven different locations and far away from it. Each location was conducted twelve experiments. From these experiments, the test results show the device works properly because there are no feature errors. The command to turn off, turn on and display the status of the lamp can be replied to properly. Need a good internet connection to get maximum results.
\end{abstract}

Keywords: remote control, telegram gateway, light control, ESP8266 module

\section{PENDAHULUAN}

Salah satu keterangan pada laman resmi Perusahaan Listrik Negara (PLN) menyatakan bahwa Tarif Tenaga Listrik mengacu pada Peraturan Menteri ESDM tahun 2016. Permen ini juga mengatur tentang Penyesuaian Tarif Tenaga Listrik (Tariff Adjustment). Penyesuaian ini dipengaruhi oleh tiga indikator, yaitu kurs (nilai tukar Dollar Amerika terhadap Rupiah), harga minyak mentah atau Indonesian Crude Price (ICP), serta inflasi[1], [2].

Saat ini semakin banyak peralatan, baik peralatan rumah tangga maupun peralatan perkantoran yang menggunakan tenaga listrik. Hal ini di satu sisi sangat membantu dan memudahkan, di sisi lain membuat beban listrik semakin bertambah. Sehingga bisa dibilang penggunaan listrik semakin boros. Terlebih lagi jika ada pengguna yang lupa mematikan peralatan listrik. Lampu listrik menjadi salah satu penyumbang terbesar penggunaan tenaga listrik[2].

Selain itu aktivitas manusia saat ini semakin meningkat dengan cepat, terlebih lagi di kota besar seperti Jakarta[2], [3]. Sehingga terkadang pekerjaan sederhana seperti mematikan lampu sering terlupakan. Hal ini menyebabkan pemborosan listrik, tidak hanya di rumah tangga tetapi juga di perkantoran.

Maka dari itu diperlukan sebuah sistem kendali lampu yang dapat mengendalikan lampu dari jarak jauh. Dibutuhkan sistem yang juga dapat melihat status lampu, apakah dalam keadaan hidup atau mati sehingga pengguna dapat mengambil keputusan untuk menghidupkan atau mematikan lampu.

Pada penelitian sebelumnya telah dibuat alat kendali listrik hanya saja masih memiliki kekurangan. Penelitian sebelumnya mencoba membuat alat kendali listrik dengan media Wireless[4], [5]. Kekurangan media wireless adalah jangkauan jarak kendalinya tidak terlalu jauh. Penelitian yang lain membuat sistem kendali dengan media Radio Frekuensi[4], [6], [7]. Jangkauan pada radio frekuensi ini 
dinyatakan maksimal 120 meter, masih terbatas pada jarak. Peneliti lain mencoba membuat sistem kendali listrik dengan media SMS[2], [8], [9]. Meskipun sudah bisa mengatasi jarak yang cukup jauh, teknologi SMS saat ini sudah jarang digunakan oleh kebanyakan orang.

Pada penelitian sebelumnya juga telah dibuat alat kendali listrik menggunakan selain Wemos D1 Mini[2], [10], [11], [12], [13], [14], [15]. Alat yang digunakan memiliki harga yang sangat jauh di atas harga Wemos D1 Mini. Hal ini bisa dipastikan dengan membuka dan melihat harga alat pada market place online.

Maka dari itu pada penelitian kali ini dibahas pembuatan alat kendali listrik yang dapat digunakan dengan jarak yang jauh dan memakan biaya yang murah.

\section{METODE PENELITIAN}

Dalam penelitian ini, metode penelitian yang digunakan untuk memperoleh informasi yang diperlukan, guna menyelesaikan sumber masalah yang ditemui. Adapun tahapan dalam metode penelitian adalah sebagai berikut:

a. Studi Literatur

Digunakan untuk menggali informasi dari berbagai sumber seperti jurnal, skripsi, makalah atau referensi lain yang bersifat valid dan relevan. Studi literatur juga digunakan untuk mengidentifikasi kebutuhan sistem yang digunakan berupa hardware, software serta mempelajari tahapan dalam merancang, implementasi dan menguji sistem.

b. Perancangan Sistem

Pada tahapan ini, sistem dirancang dengan model prototype. Baik alat yang digunakan maupun fitur yang dibuat di dalam sistem berkembang dan berubah seiring pembuatan prototype.

c. Implementasi Sistem

Dilakukan dengan merakit alat dan membangun program pada Wemos D1 Mini. Program dibangun menggunakan bahasa pemrograman C. Digunakan juga beberapa library untuk mendukung program diantaranya ESP8266WiFi, WiFiClientSecure, dan UniversalTelegramBot.

d. Pengujian Sistem

Pengujian terhadap alat dan program untuk mengevaluasi sistem yang telah dibuat. Pengujian dilakukan dengan black box testing, yaitu dengan menguji satu persatu fitur yang sudah dibuat[16], [17], [18].

\section{HASIL DAN PEMBAHASAN}

\subsection{Arsitektur Sistem}

Dalam rancangan sistem kendali ini digunakan mikrokontroler wemos d1 mini dengan modul ESP8266 di dalamnya. Komunikasi data dengan koneksi internet digunakan untuk menjembatani antara wemos d1 mini dengan telegram sehingga sistem dapat dikendalikan kapanpun dan dimanapun. Sementara modul relay sebagai switch arus listrik agar dapat menyambung dan memutuskan arus listrik terhadap lampu. Skema alat dapat dilihat pada Gambar 1. 
Vol 7 No. 2 , 2019

(C2019 Ilmu Komputer Unila Publishing Network all rights reserved

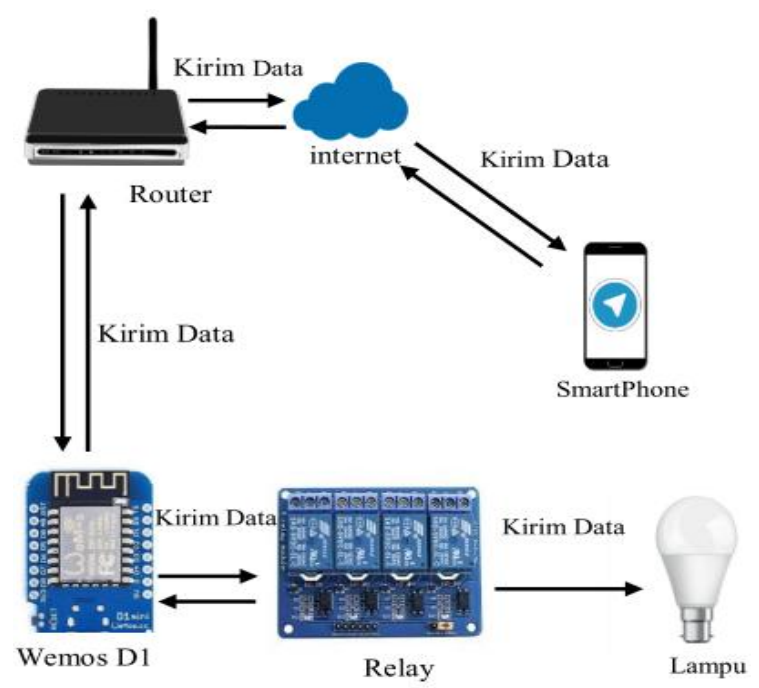

Gambar 1. Arsitektur Sistem

Dibuat satu akun telegram khusus yang akan menjadi bot untuk dapat berkomunikasi dengan pengguna. Akun bot tersebut ditanamkan ke dalam program Wemos D1 Mini untuk dapat menerima perintah dan memberikan respon terhadap permintaan pengguna. Perintah yang diterima oleh Wemos D1 Mini akan diperiksa, diolah dan diteruskan ke Modul Relay. Konektivitas antara Wemos D1 dengan relay tergambar pada Gambar 2.

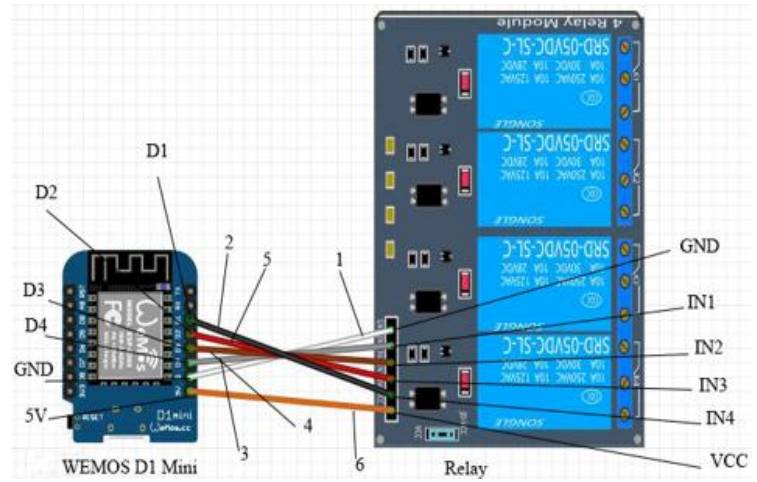

Keterangan:

Gambar 2. Konektivitas Wemos D1 dengan Relay

1. Pin GND pada Wemos dihubungkan dengan pin GND di Relay

2. Pin D1 pada Wemos dihubungkan dengan pin IN4 di Relay

3. Pin D4 pada Wemos dihubungkan dengan pin IN1 di Relay

4. Pin D3 pada Wemos dihubungkan dengan pin IN2 di Relay

5. Pin D2 pada Wemos dihubungkan dengan pin IN3 di Relay

6. Pin 5v pada Wemos dihubungkan dengan pin VCC di Relay

\subsection{Format Request}

Format request disediakan untuk pengguna kirimkan kepada akun bot. Request yang dikirim pengguna kepada bot akan diteruskan kepada Wemos D1 mini untuk diperiksa dan diteruskan ke modul relai. Format request dibuat seperti pada Tabel 1. 
Vol 7 No. 2 , 2019

(C2019 Ilmu Komputer Unila Publishing Network all rights reserved

Tabel 1. Format Request

\begin{tabular}{|c|c|}
\hline Request & Keterangan \\
\hline /options & $\begin{array}{l}\text { menampilkan semua format } \\
\text { request }\end{array}$ \\
\hline /status & $\begin{array}{c}\text { memberikan status lampu } \\
\text { hidup/mati }\end{array}$ \\
\hline /SemuaLampuOn & $\begin{array}{l}\text { perintah semua lampu menjadi } \\
\text { hidup }\end{array}$ \\
\hline /SemuaLampuOff & $\begin{array}{c}\text { perintah semua lampu menjadi } \\
\text { mati }\end{array}$ \\
\hline /lampu1on & perintah lampu 1 hidup \\
\hline /lampu1off & perintah lampu 1 mati \\
\hline /lampu2on & perintah lampu 2 hidup \\
\hline /lampu2off & perintah lampu 2 mati \\
\hline /lampu3on & perintah lampu 3 hidup \\
\hline /lampu3off & perintah lampu 3 mati \\
\hline /lampu4on & perintah lampu 4 hidup \\
\hline /lampu4off & perintah lampu 4 mati \\
\hline
\end{tabular}

\subsection{Implementasi}

Program dibuat dan ditanamkan ke Wemos D1 Mini seperti pada Gambar 3.

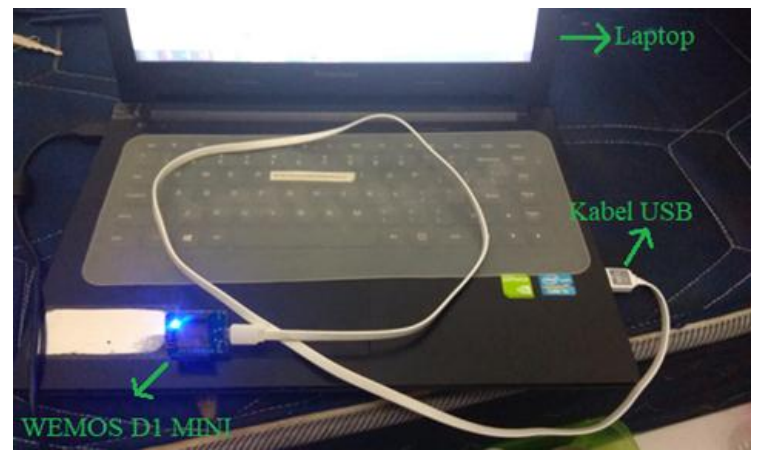

Gambar 3. Embed Program

Arus listrik oleh modul relay. Berikutnya modul relay dan lampu dirakit sedemikian rupa agar lampu dapat dihidupkan dan dimatikan seperti pada Gambar 4. Modul relay yang digunakan adalah Relay Board 4 Channel. Masing-masing channel relay menangani satu buah lampu.

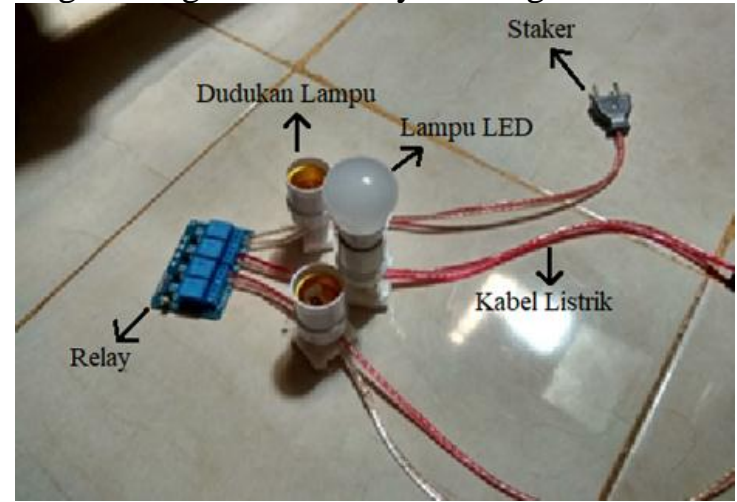

Gambar 4. Perakitan Modul Relay dan Lampu 


\subsection{Pengujian Program}

Program yang ditanamkan ke Wemos D1 Mini sudah diatur untuk terhubung ke Wifi dengan SSID juan, lalu mendapatkan IP 192.168.43.54 dan mendapat akses internet, hal ini tampak seperti pada Gambar 5.

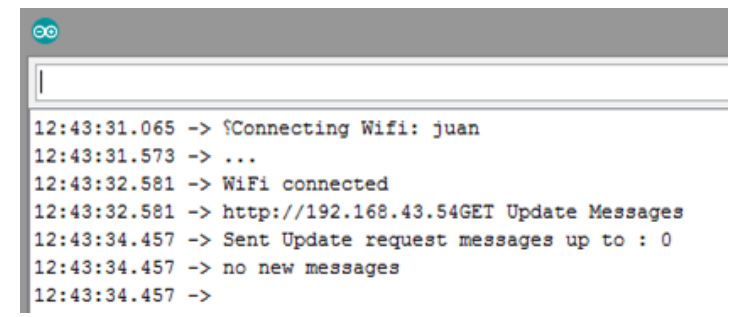

Gambar 5. Koneksi D1 Mini dengan Wifi

Setelah Wemos D1 Mini sudah terhubung dengan internet, maka berikutnya uji coba dilakukan dari sisi pengguna. Saat uji coba dilakukan akun Telegram Bot disimpan dengan nama BotBaru. Saat chat sudah dimulai, maka akan disediakan pilihan format request sesuai yang sudah dirancang pada Tabel 1 . Hasil uji coba komunikasi dengan bot seperti pada Gambar 6 .

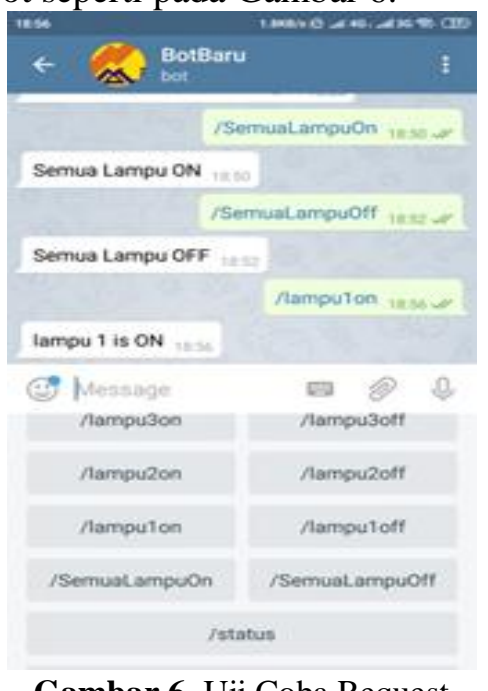

Gambar 6. Uji Coba Request

Salah satu request yang bisa digunakan adalah /SemuaLampuOn, yang digunakan untuk menghidupkan semua lampu. Perintah /SemuaLampuOn akan membuat empat buah lampu hidup sekaligus seperti ditampilkan pada Gambar 7.

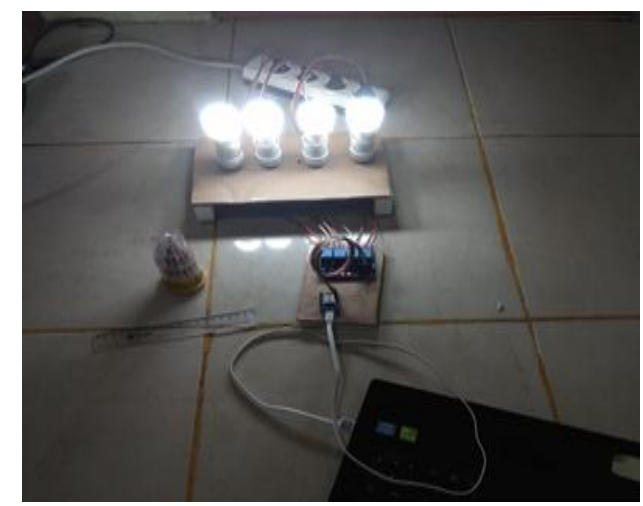

Gambar 7. Semua Lampu Hidup

Uji coba berikutnya dilakukan dengan jarak cukup jauh. Alat kendali lampu diletakkan di Desa Ulujami, Kecamatan Pesanggrahan, Jakarta Selatan. Sedangkan pengguna melakukan kendali dari jarak 
cukup jauh di beberapa lokasi berbeda. Uji coba dilakukan dua belas orang. Satu memantau dan mencatat hasil kerja alat, sedangkan yang lainnya menjadi pengguna di beberapa tempat untuk melakukan request. Sebelas orang melakukan percobaan request di tujuh tempat berbeda. Sebelas pengguna yang melakukan uji coba ini berjenis kelamin laki-laki dengan tingkat pendidikan beragam, satu orang sedang menempuh Sekolah Menengah Atas, satu orang lulusan Sarjana, dan sisanya berstatus Mahasiswa tingkat Sarjana. Di setiap lokasi dilakukan pengujian semua feature. Terdapat dua belas feature seperti terlihat pada Tabel 1, maka dilakukan dua belas pengujian di setiap lokasi. Hasil uji coba ini dituangkan dalam Tabel 2.

Tabel 2. Uji Coba Jarak Jauh

\begin{tabular}{cccc}
\hline $\begin{array}{c}\text { Lokasi } \\
\text { (Desa/Kecamatan) }\end{array}$ & $\begin{array}{c}\text { Jarak } \\
+- \\
(\mathrm{KM})\end{array}$ & $\begin{array}{c}\text { Rata-rata } \\
\text { Delay } \\
\text { (detik) }\end{array}$ & $\begin{array}{c}\text { Hasil } \\
\text { (sukses / } \\
\text { gagal) }\end{array}$ \\
\hline Kreo & 3,8 & 3 & sukses \\
Ciledug & 8,3 & 5 & sukses \\
Bintaro & 5,3 & 7 & sukses \\
Cipondoh & 15,2 & 6 & sukses \\
Kebayoran Lama & 2,7 & 4,8 & sukses \\
Karang Tengah & 10,2 & 5 & sukses \\
Peninggilan & 8,4 & 4,3 & sukses \\
\hline
\end{tabular}

Dari hasil uji coba jarak jauh, ditarik kesimpulan beberapa hal. (1) Dimanapun lokasi pengguna melakukan request kendali lampu, semua sukses dilakukan. (2) Rata-rata delay antara request dengan respon dari alat cukup cepat, yaitu hanya dalam hitungan detik. (3) Meskipun jarak dan delay belum diuji menggunakan alat uji seperti spearman maupun t-test, tapi dapat ditarik sedikit kesimpulan bahwa jarak tidak mempengaruhi waktu delay, dugaan awal yang mempengaruhi delay adalah koneksi internet yang digunakan, baik oleh pengguna maupun koneksi internet pada Wemos D1 Mini.

Setelah melakukan percobaan, sebelas pengguna tersebut mengisi kuesioner yang bersifat tertutup. Data angket berupa empat alternatif jawaban yaitu "Sangat Setuju, Setuju, Tidak Setuju, dan Sangat Tidak Setuju". Terdapat sepuluh pertanyaan di dalam kuesioner. (1) Sistem kendali ini membantu anda mengontrol lampu dari jarak jauh. (2) Sistem kendali efektif dan efisien. (3) Sering lupa mematikan lampu. (4) Sistem kendali lampu ini mempercepat pekerjaan. (5) Sistem ini sesuai dengan kebutuhan. (6) Penggunaan sistem mudah untuk dipahami. (7) Sistem berjalan dengan baik. (8) Terasa nyaman dalam menggunakan aplikasi ini. (9) Aplikasi mudah dioperasikan. (10) Secara keseluruhan penggunaan sistem ini memuaskan. Hasil dari kuesioner ini dapat dilihat dalam Gambar 8.

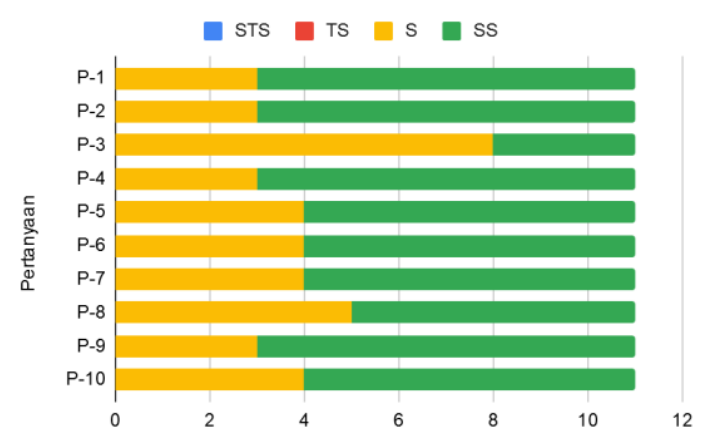

Gambar 8. Hasil Kuesioner

Dilihat dari hasil kuesioner dapat ditarik kesimpulan bahwa meskipun hanya sedikit pengguna yang lupa dalam mematikan lampu, ternyata penggunaan sistem kendali ini cukup membantu dan bermanfaat. 


\section{KESIMPULAN}

Sistem kendali lampu ini dapat memudahkan pengguna dalam mengontrol lampu dari jarak jauh, sehingga tidak perlu mematikan dan menghidupkan lampu secara manual yang berada pada setiap ruangan. Tidak hanya untuk menghidupkan dan mematikan lampu, sistem ini dapat digunakan untuk melakukan pengecekan status lampu. Sistem ini mampu mengatasi rasa khawatir akan borosnya listrik yang disebabkan lupa mematikan lampu dan tidak berada di lokasi/ruangan lampu berada. Selama terhubung ke internet, pengguna dapat menggunakan sistem kendali di mana saja. Mudah digunakan karena sistem dikendalikan menggunakan media sosial telegram. Berdasarkan kuesioner yang disebarkan dapat disimpulkan bahwa aplikasi ini dapat membantu dalam memantau dan mengendalikan listrik dari manapun dan kapanpun.

Pengembangan yang bisa dilakukan pada penelitian berikutnya diantaranya dengan menyimpan log pengguna yang melakukan memberikan perintah menghidupkan atau mematikan lampu. Selain itu bisa juga ditambahkan fitur management user guna menentukan pengguna yang berhak melihat status, mematikan dan menghidupkan lampu tertentu.

\section{DAFTAR PUSTAKA}

[1] PLN, "Tarif Tenaga Listrik," Listrik Untuk Kehidupan yang Lebih Baik - PT PLN (Persero). [Online]. Available: https://www.pln.co.id/pelanggan/tarif-tenaga-listrik. [Accessed: 10-Sep2019].

[2] R. D. Risanty and L. Arianto, "RANCANG BANGUN SISTEM PENGENDALIAN LISTRIK RUANGAN DENGAN MENGGUNAKAN ATMEGA 328 DAN SMS GATEWAY SEBAGAI MEDIA INFORMASI," JUST IT : Jurnal Sistem Informasi, Teknologi Informasi dan Komputer, vol. 7, no. 2, pp. 45-54, 2017.

[3] M. Ichwan, M. G. Husada, and M. I. A. Rasyid, "Pembangunan Prototipe Sistem Pengendalian Peralatan Listrik pada Platform Android," Jurnal Informatika, vol. 4, no. 1, pp. 13-25, 2013.

[4] S. Tharishny, S. Selvan, and P. Nair, "Android based smart house control via wireless communication," International Journanl of Scientific Engineering and Technology,(5), pp. 323 $325,2016$.

[5] A. S. Kadalla, A. I. Tijjani, and M. K. Luka, "Android Based Smart Home System," in International Conference on African Development Issues, 2016.

[6] D. Satria and H. Ahmadian, "Perancangan Sistem Pengendalian Perangkat Listrik Rumah Tangga Berbasis Radio Frekuensi YS1020UB dan Mikrokontroler ATMEGA16," Journal of Islamic Science and Technology, vol. 2, no. 2, pp. 193-202, 2006.

[7] S. Yanuar, G. Prabowo, and E. Purwanto, "PEMBUATAN PERALATAN PENGUKURAN PEMAKAIAN DAYA LISTRIK DI TIGA LAB ELEKTRO INDUSTRI PENS-ITS DAN MONITORING JARAK JAUH (RF Modules, Software Aplikasi PC dan Database)," eepis final project, 2009.

[8] H. F. Imron, R. Rizal Isnanto, and E. D. Widianto, "Perancangan Sistem Kendali pada Alat Listrik Rumah Tangga Menggunakan Media Pesan Singkat (SMS)," Jurnal Teknologi dan Sistem Komputer, vol. 4, no. 3, pp. 454-462, 2016.

[9] B. Novianto, S. Winardi, and T. P. Rusmiardi, "Rancang Bangun Kendali dan Monitoring Lampu dengan Teknologi Short Messege Service (SMS)," Univ. Narotama, 2012. 
[10] H. S. T. Simbolon, R. Rumani M, and R. E. Saputra, "Rancang Bangun Sistem Otomasi dan Keamanan Rumah Pintar Menggunakan Raspberry Pi 3 dengan Pusat Kendali Telegram," eProceedings of Engineering, vol. 5, no. 1, 2018.

[11] I. T. Baskoro, D. Darjat, and S. Sudjadi, "PERANCANGAN PENGONTROLAN NYALA LAMPU DAN KIPAS ANGIN PADA SEBUAH RUANGAN MENGGUNAKAN RASPBERRY PI MODEL B DENGAN WEB GUI," Transient: Jurnal Ilmiah Teknik Elektro, vol. 3, no. 4, pp. 567-571, 2015.

[12] D. Prihatmoko, "Pemanfaatan Raspberry Pi Sebagai Server Web Untuk Penjadwalan Kontrol Lampu Jarak Jauh,” JURNAL INFOTEL, vol. 9, no. 1, pp. 84-91, 2017.

[13] S. Tomasua, D. Triyanto, and I. Nirmala, "SISTEM KENDALI DAN MONITORING PENGGUNAAN PERALATAN LISTRIK DI RUMAH MENGGUNAKAN RASPBERRY PI DAN WEB SERVICE," Coding Jurnal Komputer dan Aplikasi, vol. 4, no. 3, 2016.

[14] M. R. Nurkamiden, M. E. I. Najoan, and M. D. Putro, "Rancang Bangun Sistem Pengendalian Perangkat Listrik Berbasis Web Server Menggunakan Mini PC Raspberry Pi Studi Kasus Gedung Fakultas Teknik Universitas Sam Ratulangi," Jurnal Teknik Informatika, vol. 11, no. 1, 2017.

[15] L. Kunarso, "RANCANG BANGUN SISTEM KONTROL LISTRIK BERBASIS WEB MENGGUNAKAN SERVER ONLINE MINI PC RASPBERRY PI," UNIVERSITAS STIKUBANK, 2015.

[16] M. E. Khan, "Different Approaches to Black Box Testing Technique for Finding Errors," International Journal of Software Engineering \& Applications, vol. 2, no. 4, p. 31, 2011.

[17] M. E. Khan and F. Khan, "A Comparative Study of White Box, Black Box and Grey Box Testing Techniques," Int. J. Adv. Comput. Sci. Appl, 2012.

[18] S. Nidhra and J. Dondeti, "Black Box and White Box Testing Techniques-a Literature Review," International Journal of Embedded Systems and Applications (IJESA) , vol. 2, no. 2, pp. 29-50, 2012. 